\title{
SIGNIFIKANSI PENDIDIKAN ANAK DALAM PERSPEKTIF ALKITAB
}

\author{
Maria Lidya Wenas \& I Putu Ayub Darmawan \\ Sekolah Tinggi Teologi Simpson, Ungaran \\ Jl. Agung No. 66, Krajan, Kel. Susukan, \\ Kec. Ungaran Timur, Kab. Semarang, Jawa Tengah (50526) \\ Email: putuayub@sttsimpson.ac.id
}

\begin{abstract}
Maria Lidya Wenas \& I Putu Ayub Darmawan, Significance Children Education in Biblical Perspective. Education of children is important in human life. Formulation of the problem in this research is how the Bible perpsektif about children's education? The purpose of this study is to outline perpsektif Bible about children's education. Types of research in this paper is the qualitative research literature. The object of this study is a biblical perspective on the education of children. In this study, researchers conducted a literature study to be able to explore and understand the biblical view of children's education. In this study, the authors sought feedback from a grasp of Hebrew and Greek. This is to avoid the use of verses in Hebrew and Greek avoid deviations. From this study showed that (1) Education of children as the planting of faith; (2) Education of children as a process of knowledge transfer; (3) the child's education as a process of value investment.
\end{abstract}

Keywords: Children Education, Christian Education, Biblical Principles.

ABSTRAK:Maria Lidya Wenas \&I Putu Ayub Darmawan, Signifikansi Pendidikan Anak Dalam Perspektif Alkitab. Pendidikan anak merupakan hal yang penting dalam kehidupan manusia. Rumusan masalah dalam penelitian ini adalah bagaimana perpsektif Alkitab tentang pendidikan anak? Tujuan dari penelitian ini adalah memaparkan perpsektif Alkitab tentang pendidikan anak. Jenis penelitan dalam karya tulis ini adalah penelitian kualitatif studi pustaka. Objek penelitian ini adalah perspektif Alkitab tentang pendidikan anak. Dalam penelitian ini, peneliti melakukan studi literatur untuk dapat menggali dan memahami pandangan Alkitab tentang pendidikan anak. Dalam penelitian ini penulis meminta masukan dari seorang yang memahami tentang Bahasa Ibrani dan Bahasa Yunani. Hal tersebut dilakukan agar penggunaan ayat-ayat dalam Bahasa Ibrani dan Bahasa Yunani tidak terjadi penyimpangan. Dari penelitian ini diperoleh hasil yaitu (1) Pendidikan anak sebagai proses penanaman iman; (2) Pendidikan anak sebagai proses transfer pengetahuan; (3) pendidikan anak sebagai proses penanaman nilai.

Kata Kunci: Pendidikan Anak, Pendidikan Kristen, Prinsip Alkitab.

\section{PENDAHULUAN}

Pendidikan merupakan bagian penting dalam usaha memajukan kehidupan manusia maupun sebuah bangsa. Sabar Budi Raharjo menuliskan bahwa "Telah menjadi keyakinan semua bangsa di dunia, bahwa pendidikan mempunyai peran yang sangat besar dalam kemajuan bangsa."1 Nggoro juga menjelaskan bahwa bagi John Locke pendidikan merupakan hal yang sangat perlu bagi manusia. ${ }^{2}$ Pendidikan merupakan sebuah investasi yang sangat ber-

${ }^{1}$ Sabar Budi Raharjo, "Evaluasi Trend Kualitas Pendidikan di Indonesia," Jurnal Penelitian dan Evaluasi Pendidikan, Tahun 16, Nomor 2, (2012):513.

${ }^{2}$ Adrianus Marselus Nggoro, "Filosifi Wuat Wa'i Budaya Manggarai Dari Perspektif Demokrasi Pancasila," Jurnal Pendidikan dan Kebudayaan Missio, Volume 7, Nomor 1, (Januari 2015):102. harga. Kemudian Pendidikan Kristen merupakan pendidikan yang bertujuan untuk memimpin setiap murid pada pengenalan akan Kristus dan kedewasaan di dalam Kristus. Jadi pendidikan merupakan sebuah hal yang penting dan memiliki tujuan yang bersentuhan langsung dengan kehidupan manusia. Yari Dwikurnaningsih mengungkapkan bahwa "Pada dasarnya setiap pendidik mendambakan anak-anak yang cerdas dan berperilaku baik dalam kehidupan sehari-harinya." 3 Tujuan dari hal itu adalah kelak anak yang dididik dengan baik menjadi anak-anak

${ }^{3}$ Yari Dwikurnaningsih, "Peran Guru Dalam Pendidikan Anak," Satya Widya, Volume 27, Nomor 2, (Desember 2011): 235. 
yang unggul dan mampu menghadapi sagala situasi yang menjadi tantangan di masa depan.

Pendidikan juga memiliki sebuah landasan berpikir, landasan bertindak, dan panduannya. Dalam Pendidikan Kristen,Alkitab merupakan landasan berpikir, landasan bertindak, dan rule-nya. Secara umum dalam Alkitab banyak berbicara tentang proses pendidikan dan pentingnya proses pendidikan. Sebagai sebuah dasar pendidikan, maka ada banyak hal yang berkaitan dengan pelaksanaan pendidikan Kristen dalam Alkitab perlu digali dengan lebih mendalam. Perlu untuk disadari bahwa pelaksanaan pendidikan Kristen dari sejak lahirnya tidak dapat lepas dari Alkitab. Dalam pelaksanaan pendidikan Kristen di Gereja, Keluarga, dan Sekolah pendidikananak merupakan bagian penting yang dilaksanakan secara terus menerus dan menjadi sebuah isu penting yang perlu dibahasdalam hal praktis maupun teoritis. Di dalam Gereja, pendidikan anak juga menjadi bagian penting pelaksanaan pembinaan warga jemaat. Dalam konteks pendidikan sekolah, pendidikan Anak kini berkembang menjadi sebuah Lembaga Pendidikan Anak Usia Dini (PAUD). Rifa'i menuliskan dalam jurnalnya bahwa pendidikan anak, sebagai bagian pendidikan untuk semua, telah memperoleh perhatian dari pengambil kebijakan pendidikan dalam forum pendidikan dunia. ${ }^{4}$ Sementara perhatian keluarga terhadap pendidikan anak masih menjadi perdebatan dalam pelaksanaanya, tetapi tetap menjadi sebuah perhatian penting untuk dilaksanakan. Memang ada kecenderungan untuk menyerahkan pendidikan anak dari orangtua kepada sekolah atau gereja.Untuk itu perlu dipahami apa yang menjadi perspektif Alkitab tentang pendidikan anak.Wiersbe mengatakan bahwa hidup tidaklah mudah bagi anak-anak, terutama anak-anak Kristen. Masalah yang dihadapi oleh anak-anak dapat terlihat sebagai masalah yang kecil bagi orang dewasa, tetapi bagi mereka itu ada-

${ }^{4}$ Achmad Rifa'i RC, "Model Pengelolaan Program Pendidikan Anak Usia Dini Berbasis Masyarakat," Jurnal Ilmu Pendidikan, Volume 19, Nomor 1, (Juni 2013): 120 . lah masalah yang cukup besar. ${ }^{5}$ Oleh sebab itu anakanak perlu ditolong, anak-anak dididik untuk menghadapi masalah yang mereka hadapi.

Rumusan masalah dalam penelitian ini adalah bagaimana perpsektif Alkitab tentang pendidikan anak? Tujuan dari penelitian ini adalah memaparkan perpsektif Alkitab tentang pendidikan anak.

\section{METODE}

Penelitian ini merupakan penelitian kualitatif studi pustaka. Objek penelitian ini adalah perspektif Alkitab tentang pendidikan anak. Dalam penelitian ini, peneliti melakukan studi literatur untuk dapat menggali dan memahami pandangan Alkitab tentang pendidikan anak.Penelitian ini juga memanfaatkan prinsip-prinsip hermeneutika Alkitab atau penafsiran Alkitab.

Sumber yang digunakan dalam penelitian ini adalah (1) Alkitab versi King James Version; (2) Biblical Hebrew teks with vowel points (BHvp); (3) Interlinear Greek New Testament (IGNT); (4)Alkitab Indonesia Terjemahan Baru (TB). Penelitian ini juga memanfaatkan aplikasi Sabda (OLB versi Indonesia) Versi 4.30, 6 September 2013. Kutipan ayat-ayat Alkitab dalam beberapa bahasa diambil dari aplikasi SABDA (OLB versi Indonesia) Versi 4.30. Sumbersumberberupa bahan-bahan interpretatif seperti (1) Tafsiran-tafsiran Matthew Henry; (2) Tafsiran Surat Efesus karya Peter T. O'Brien; (3) Tafsiran Injil Matius karya Leon Morris; (4) Tafsiran-tafsiran karya Warren W. Wiersbe. Kemudian penulis menggunakan bahanbahan faktual seperti (1) The New Strong's Exhaustive Concordance of The Bible karya James Strong; (2) Perjanjian Baru Interlinier \& Konkordansi (PBIK); (3) Alkitab Edisi Studi; (4) Alkitab Penuntun Hidup Berkelimpahan; dan (5) Ensiklopedi Alkitab. Beberapa buku yang berkaitan dengan pendidikan anak dan tafsiran-tafsiran Alkitab juga digunakan untuk mendukung pembahasan dalam penelitian ini. Hasil studi

${ }^{5}$ Warren W. Wiersbe, Utuh Di Dalam Kristus (Bandung: Kalam Hidup, 2001), 112. 
dari sumber-sumber tersebut kemudian penulis uraikan secara deskriptif dan ditarik sebuah ikhtisar berkaitan dengan pendidikan anak.

Prinsip studi Alkitab yang digunakan dalam penelitian ini mengacu pada Scheunemann dalam bukunya yang berjudul, Panduan Lengkap Penafsiran Alkitab Perjanjian Lama \& Perjanjian Baru. Dalam penelitian ini penulis mengajukan pertanyaanpertanyaan sehubungan dengan konteks dan teks, kemudian maksud teks dikontrol oleh makna teks dan tidak boleh bertentangan antara satu dengan yang lainnya. ${ }^{6}$ Dalam pelaksanaan penelitian, penulis melakukan penyesuaian dengan penelitian yang dilaksanakan.

Gambar 1. Proses Penelitian



Karena pentingnya menjaga keabsahan data, maka dalam penelitian ini penulis meminta masukan

${ }^{6}$ Rainer Scheunemann, Panduan Lengkap Penafsiran Alkitab Perjanjian Lama \& Perjanjian Baru, Menafsirkan Alkitab dengan Metode Ilmiah-Eksegetis (Yogyakarta: PBMR Andi, 2009), 26. dari seorang pakar. Hal tersebut dilakukan agar penggunaan ayat-ayat dalam Bahasa Ibrani dan Bahasa Yunani tidak terjadi penyimpangan. Proses penelitian ini dilaksanakan dalam 9 tahapan mulai dari tahap rancangan hingga tahap perbaikan laporan.

\section{HASIL}

\section{Daftar Ayat Alkitab}

Hasil dari tahap pengumpulan ayat Alkitab adalah terkumpulnya ayat-ayat Alkitab yang terkait dengan topik penelitian. Adapun daftar ayat-ayat tersebut adalah: Keluaran 12:24-27, Ulangan 6:4-9, Mazmur 78:5-6, Injil Matius 19:14, Injil Markus 10:13-16, Injil Lukas 18:16, Surat Efesus 6:1, Surat Kolose 3:20. Ayat-ayat tersebut kemudian digali dan diuraikan maknanya sehingga dapat memberi gambaran signifikasi pendidikan anak dalam Alkitab.

\section{Pendidikan Anak Dalam Perspektif Alkitab}

\section{Keluaran 12:24-27}

Kitab Keluaran pasal 12:24-27 dituliskan tentang tanggungjawab orangtuauntuk mendidik anakanak agar tetap menjaga tradisi ibadah Paskah. Berikut teks Keluaran 12:24-27 dalam Alkitab Bahasa Indonesia, ayat tersebut diterjemahkan demikian:

Kamu harus memegang ini sebagai ketetapan sampai selama-lamanya bagimu dan bagi anakanakmu. Dan apabila kamu tiba di negeri yang akan diberikan TUHAN kepadamu, seperti yang difirmankan-Nya, maka kamu harus pelihara ibadah ini. Dan apabila anak-anakmu berkata kepadamu: Apakah artinya ibadahmu ini? maka haruslah kamu berkata: Itulah korban Paskah bagi TUHAN yang melewati rumah-rumah orang Israel di Mesir, ketika Ia menulahi orang Mesir, tetapi menyelamatkan rumah-rumah kita." Lalu berlututlah bangsa itu dan sujud menyembah. ${ }^{7}$

${ }^{7}$ Keluaran 12:26-27, Alkitab, Terjemahan Baru (Jakarta: LAI, 2008). Dalam catatan kaki berikutnya, kutipan dari Alkitab hanya akan ditulis alamat ayat. 
Secara keseluruhan Keluaran 12 berbicara tentang peristiwa $\mathrm{Paskah}^{8}$ dan keluarnya bangsa Israel dari Mesir. Ayat 1-23 mencatat bahwa Tuhan berfirman kepada Musa dan Harun tentang perayaan Paskah. Ayat 24-28 kemudian mencatat bahwa Musa, Harun dan seluruh bangsa Israel harus memegang ketetap-

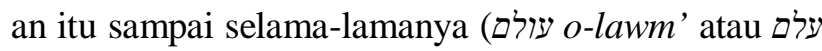
o-lawm') $)^{9}$ bagi orang tua dan anak-anak. Dalam artikel tentang Paskah pada Alkitab Penuntun Hidup Berkelimpahan dituliskan bahwa sejak peristiwa yang bersejarah itu, bangsa Israel senantiasa merayakan Paskah pada musim semi sebagai sikap taat pada perintahNya bahwa paskah merupakan "ketetapan untuk selama-lamanya (Kel. 12:14). ${ }^{10}$ Hasil dari proses pendidikan adalah sikap yang taat kepada Allah (Kel. 12:28). Stamps dalam catatan kaki untuk Alkitab Penuntun Hidup Berkelimpahan menuliskan bahwa dalam ayat ini,

Orangtua diharapkan memakai Paskah untuk mengajarkan kebenaran kepada anak-anak mereka tentang bagaimana Allah menebus mereka dari perbudakan dan dosa serta menjadikan mereka umat istimewa yang diperhatikan dan diperintahkan oleh-Nya. ${ }^{11}$

Orangtua memiliki kuasa untuk mendidik anak-anak mereka dan harus digunakan untuk mendidik mereka agar memahami karya Allah dalam kehidupan mereka.

Dari Keluaran 12:24-27, prinsip penting pendidikan adalah secara terus menerus, orangtua bertanggungjawab untuk mendidik anak-anak agar me-

${ }^{8}$ Perayaan Paskah diselenggarakan untuk mengenang tindakan Allah yang telah menyelamatkan umat dari tulah terakhir dan keluar dari perbudakan di Mesir. Lihat Alkitab Edisi Studi (Jakarta: LAI, 2012), 1713.

${ }^{9}$ Dapat diartikan ever, everlasting, old, perpetual, evermore, never, time, ancient, world, always, alway, long, more. James Strong, The New Strong's Exhaustive Concordance of The Bible (London: Thomas Nelson Publishers, 1984), s.v. עולם.

${ }^{10}$ Donald C. Stamps, "Paskah," Alkitab Penuntun Hidup Berkelimpahan (Jakarta: LAI bekerjasama dengan Gandum Mas, 2003), 112.

${ }^{11}$ Donald C. Stamps, Catatan kaki pada Alkitab Penuntun Hidup Berkelimpahan (Jakarta: LAI bekerjasama dengan Gandum Mas, 2003), 114. reka memahami makna paskah. Apabila anak bertanya tentang apa arti ibadah yang dilakukan maka orangtua berkewajiban untuk menjawab pertanyaan anakanak dengan tepat.

\section{Ulangan 6:4-9}

Kitab Ulangan merupakan salah satu kitab dalam Perjanjian Lama yang terdapat ayat tentang pendidikan anak. Berikut teks Ulangan 6:4-9 dalam Biblical Hebrew Teks With Vowel Points ${ }^{12}$ :

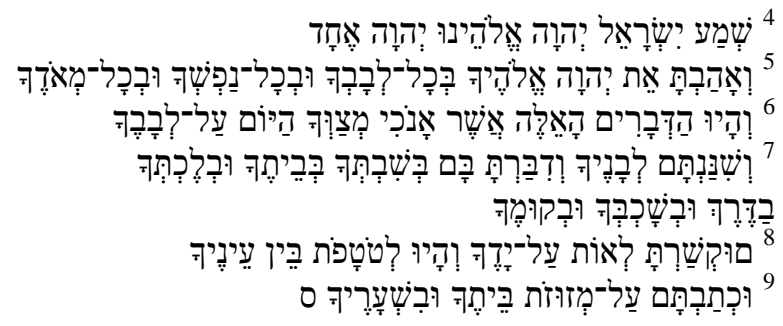

Dalam Alkitab Bahasa Indonesia, ayat tersebut diterjemahkan demikian:

Dengarlah, hai orang Israel: TUHAN itu Allah kita, TUHAN itu esa! Kasihilah TUHAN, Allahmu, dengan segenap hatimu dan dengan segenap jiwamu dan dengan segenap kekuatanmu. Apa yang kuperintahkan kepadamu pada hari ini haruslah engkau perhatikan, haruslah engkau mengajarkannya berulang-ulang kepada anak-anakmu dan membicarakannya apabila engkau duduk di rumahmu, apabila engkau sedang dalam perjalanan, apabila engkau berbaring dan apabila engkau bangun. Haruslah juga engkau mengikatkannya sebagai tanda pada tanganmu dan haruslah itu menjadi lambang di dahimu, dan haruslah engkau menuliskannya pada tiang pintu rumahmu dan pada pintu gerbangmu. ${ }^{13}$

Kata dengarlah (מעש shaw-mah') ${ }^{14}$ merupakan sebuah kata yang sering diucapkan dalam ibadah di Sinagoge. Ada perintah ganda yang mengikuti kata shama kepada bangsa Israel, yaitu (1) perintah untuk mengasihi Allah dengan segenap hati, dengan segenap jiwa, dan dengan segenap kekuatan (ay. 5-6); (2) perintah kedua adalah untuk mengajarkan iman mereka

12“Biblical Hebrew Teks With Vowel Points," SABDA (OLB versi Indonesia) Versi 4.30, 6 September 2013.

\footnotetext{
${ }^{13}$ Ulangan 6:4-7.

${ }^{14}$ Strong, The New Strong's Exhaustive, s.v. מעש.
} 
dengan tekun kepada anak-anak mereka (ay. 7-9). ${ }^{15}$ Kemudian ungkapan "haruslah engkau mengajarkannya berulang-ulang" (ניש shaw-nan') dapat berarti mengasah, mempertajam, mengajar dengan tekun. ${ }^{16}$ Ayat tersebut menujukkan sebuah tindakan intensif dan mengekspresikan suatu tindakan yang rampung.

Dalam hubungannya dengan waktu, tindakan ini mungkin:

1a) Tindakan yang baru saja rampung dari sudut pandang sekarang. Contoh: "I have come" to tell you the news; 1b) Tindakan yang rampung lebih ke atau kurang dari jarak masa lampau. Contoh: In the beginning God "created" "I was (once) young" and "I have (now) grown old" but "I have not seen" a righteous man forsaken; 1c) Tindakan yang telah rampung dari sudut pandang tindakan yang lain di masa lampau. Contoh: God saw everything that "he had made"; 1d) Tindakan yang rampung dari sudut pandang tindakan yang lain di masa depan. Contoh: I will draw for thy camels also until "they have done" drinking. ${ }^{17}$

Dengan demikian pendidikan anak merupakanperintah untuk mengajarkanorang tua dengan tekun kepada anak-anak dan merupakan sebuah tindakan yang intensif berupa mengajar anak dalam setiap kesempatan seperti mengajarkannya berulang-ulang, membicarakannya apabila engkau duduk di rumahmu, apabila engkau sedang dalam perjalanan, apabila engkau berbaring dan apabila engkau bangun.

\section{Mazmur 78:5-6}

Mazmur juga merupakan salah satu kitab dalam Perjanjian Lama yang terdapat ayat tentang pendidikan anak. Berikut teks Mazmur 78:5-6 dalam Biblical Hebrew Teks With Vowel Points ${ }^{18}$ :



${ }^{15}$ Stamps, Catatan kaki pada Alkitab Penuntun, 285.

${ }^{16}$ Strong, The New Strong's Exhaustive, s.v. נוש.

17"Leksikon Ibrani", SABDA (OLB versi Indonesia) Versi 4.30, 6 September 2013.

18"Biblical Hebrew Teks With Vowel Points."
Dalam Alkitab Bahasa Indonesia, ayat tersebut diterjemahkan demikian:

Telah ditetapkan-Nya peringatan di Yakub dan hukum Taurat diberi-Nya di Israel; nenek moyang kita diperintahkan-Nya untuk memperkenalkannya kepada anak-anak mereka, supaya dikenal oleh angkatan yang kemudian, supaya anak-anak, yang akan lahir kelak, bangun dan menceritakannya kepada anak-anak mereka. ${ }^{19}$

Matthew Henry menjelaskan bahwa ayat ini merupakan sebuah peringatan yang ditetapkan-Nya atau kovenan dan tidak dimaksudkan sebagai suatu res unius cetatis - satu hal untuk satu angkatan, melainkan sebuah peringatan yang harus dipelihara atau diteruskan secara terus-menerus dari satu angkatan ke angkatan berikutnya. ${ }^{20}$

Kata עי ער (yada') yang digunakan dalam ayat ini dapat diartikan sebagai pengetahuan, menganggap, memberitakan, mengatakan, memahami, menyatakan, dan mengajar. ${ }^{21}$ Dalam hal ini ada sebuah perintah untuk secara terus menerus mendidik anakanak untuk mengenal Taurat atau perintah Tuhan, sehingga bila satu angkatan berlalu maka angkatan berikutnya tidak akan turut berlalu tetapi bangkit sebagai generasi penerus. Dalam konteks bangsa Israel, bagian ayat ini menunjukkan agar mereka terus memperhatikan Taurat dan tidak mengikuti contoh nenek moyang mereka (Mzm. 78:8). Sebagai keturunan Abraham, nenek moyang bangsa Israel telah mengikat kovenan dengan Allah, sifat mereka memberontak dan dianggap sebagai angkatan yang durhaka, serta jiwa mereka tidak setia kepada-Nya. ${ }^{22}$ Implikasi ayat ini bagi pendidikan anak adalah setiap anak harus dididik secara terus menerus sebagai proses alih budaya, alih pengetahuan, dan alih nilai.

\footnotetext{
${ }^{19}$ Mazmur 78:5-6.

${ }^{20}$ Matthew Henry, Tafsiran Matthew Henry: Ki-
} tab Mazmur 51-100,Terj. Iris Ardaneswari, dkk. (Surabaya: Momentum, 2012), 1118.

${ }^{21}$ Strong, The New Strong's Exhaustive, s.v. ידע.

${ }^{22}$ Henry, Tafsiran Matthew Henry: Kitab Mazmur 51-100, 1119. 


\section{Injil-Injil Sinoptis}

Di dalam Injil Matius19:14 dituliskan perkataan Yesus mengenai anak-anak. Perkataan itu dituliskan dalam Interlinear Greek New Testament de-



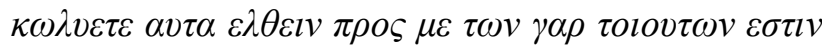

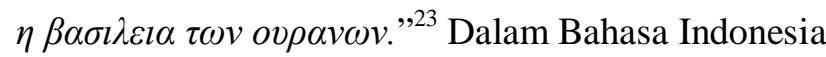
dituliskan demikian: "Biarkanlah anak-anak itu, janganlah menghalang-halangi mereka datang kepada$\mathrm{Ku}$; sebab orang-orang yang seperti itulah yang empunya Kerajaan Sorga." ${ }^{24}$

Injil Markus 10:13-16 juga mencatat hal yang sama dengan Matius 19:14. Dalam Interlinear Greek New Testamentayat Markus 10:14 dituliskan demikian " $\delta \omega v$ $\delta \varepsilon$ o $\alpha \varphi \varepsilon \tau \varepsilon \quad \tau \alpha \quad \pi \alpha l \delta l \alpha \quad \varepsilon \rho \chi \varepsilon \sigma \theta \alpha l \quad \pi \rho o \varsigma \mu \varepsilon \kappa \alpha l \mu \eta \quad \kappa \omega \lambda v \varepsilon \tau \varepsilon$

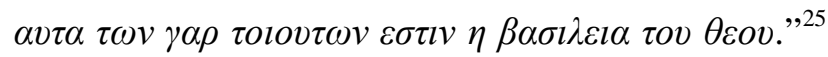
Dalam Alkitab Bahasa Indonesia ayat tersebut diterjemahkan sebagai berikut

Ketika Yesus melihat hal itu, Ia marah dan berkata kepada mereka: "Biarkan anak-anak itu datang kepada-Ku,jangan menghalang-halangi mereka, sebab orang-orang yang seperti itulah yang empunya Kerajaan Allah. ${ }^{26}$

Demikian pula Injil Lukas 18:16 menuliskan hal yang sama dengan Matius 19:14 dan Markus 10:13-16. Dalam Interlinear Greek New Testament

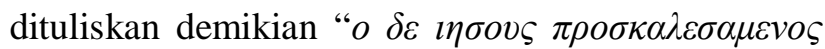
$\alpha \nu \tau \alpha \varepsilon l \pi \varepsilon v \alpha \varphi \varepsilon \tau \varepsilon \tau \alpha \pi \alpha l \delta l \alpha \varepsilon \rho \chi \varepsilon \sigma \theta \alpha l \pi \rho \circ \mu \varepsilon \kappa \alpha l \mu \eta$


$\theta \varepsilon o v .{ }^{, 27}$ Dalam Bahasa Indonesia ayat tersebut diterjemahkan demikian:

Tetapi Yesus memanggil mereka dan berkata: "Biarkanlah anak-anak itu datang kepada-Ku, dan jangan kamu menghalang-halangi mereka, sebab orang-orang yang seperti itulah yang empunya Kerajaan Allah."28

23"Interlinear Greek New Testament", SABDA (OLB versi Indonesia) Versi 4.30, 6 September 2013.

${ }^{24}$ Matius 19:14.

25"Interlinear Greek New Testament."

${ }^{26}$ Markus 10:14

${ }^{27}$ "Interlinear Greek New Testament."

${ }^{28}$ Lukas 18:16.
Ayat-ayat tersebut menunjukkan bahwa Yesus ingin agar anak-anak kecil ( $\pi \alpha \iota \delta ı o v$, paidion) datang pada-Nya dan jangan ada yang melarang ( $\kappa \omega \lambda v \omega$, koluo) mereka datang pada Yesus. Sebelum peristiwa yang diceritakan dalam ayat tersebut, telah terjadi suatu situasi dimana murid-murid-Nya memarahi orang-orang yang membawa anak-anak kecil kepada Yesus Kristus. Yesus Kristus menghardik para murid karena tindakan mereka. Matthew Henry mengatakan bahwa

Murid-murid menghalangi anak-anak dibawa kepada Yesus Kristus, seolah-olah mereka tahu pasti pikiran Guru mereka dalam hal ini, padahal belum lama berselang Ia memperingatkan mereka untuk tidak menyesatkan anak-anak. ${ }^{29}$

Sementara Leon Morris menjelaskan bahwa sikap para murid terhadap anak-anak itu jelas berbeda dengan sikap Yesus Kristus, dan mereka tidak dapat memahami mengapa guru mereka harus direpotkan dengan anak-anak kecil. Itu sebabnya Yesus Kristus marah terhadap sikap para murid. Lebih lanjut Leon Morris menjelaskan bahwa dalam peristiwa tersebut, khususnya yang tercatat dalam Injil Markus, menunjukkan bahwa Yesus Kristus sangat marah dengan tindakan yang dilakukan oleh murid-murid-Nya. ${ }^{30}$

Dalam ayat-ayat tersebut, Yesus Kristus berbicara terkait dengan anak-anak yang datang kepadaNya. Fokus perhatian Yesus Kristus dalam pelayanan yang dilakukan-Nya pada saat itu adalah anakanak.Kata biarkanlah (Yun.: $\alpha \varphi \imath \eta \mu l$,aphiemi) dapat dimak-nai sebagai biarkanlah, biarlah ... menurutiNya, memperkenankannya, menyerahkan, serahkanlah. ${ }^{31}$ Matthew Henry menjelaskan bahwa kemungkinan yang membawa anak-anak saat itu adalah orang tua, penjaga atau pengasuh (paedagogos). Lebih lanjut Matthew Henry menjelaskan bahwa orang-

${ }^{29}$ Matthew Henry, Tafsiran Matthew Henry: Injil Markus, Terj. Lanny Murtihardjana, dkk. (Surabaya: Momentum, 2011), 219.

${ }^{30}$ Leon Morris, Injil Matius (Surabaya: Momentum, 2016), 496.

${ }^{31}$ Strong, The New Strong's Exhaustive, s.v. $\alpha \varphi \imath \eta \mu$. 
orang yang datang membawa anak-anak itu memandang Yesus Kristus sebagai pribadi yang luar biasa. Mereka ingin agar Yesus Kristus bersedia memberkati anak-anak itu, melalui penumpangan tanganNya. ${ }^{32}$

Dalam tafsirannya, Matthew Henry memberikan penjelasan akan ayat tersebut sebagai berikut:

Ia memerintahkan supaya anak-anak tersebut dibawa kepada-Nya, dan tidak boleh ada perkataan atau perbuatan apa pun untuk menghalangi mereka. Biarkan anak-anak kecil, segera setelah mereka mampu berdiri sendiri, untuk datang kepada-Ku, sehingga mereka bisa memanjatkan doa permohonan mereka kepada-Ku dan menerima pengajaran dari-Ku. ${ }^{33}$

Dalam tafsiran Injil Lukas, Matthew Henry menekankan hal yang serupa bahwa ada sebuah kepedulian dari Yesus, Sang Guru Agung, kepada jiwa anakanak yang datang kepada-Nya. ${ }^{34}$ Ia menaruh perhatian yang luar biasa pada anak-anak.

Berkaitan dengan pendidikan, dalam ayat tersebut terkandung sebuah pesan bahwa anak-anak memerlukan sebuah perhatian termasuk dalam hal ini adalah perhatian dalam pendidikan. Yesus Kristus, Sang Guru Agung menaruh sebuah perhatian penting pada anak-anak, Ia mengingatkan para murid agar tidak melarang anak-anak datang kepada-Nya. Selain itu dalam pengajaran-Nya, Ia beberapa kali menggunakan anak-anak sebagai sebuah contoh.

\section{Surat Efesus 6:1}

Dalam surat Paulus kepada jemaat di Efesus Paulus menyinggung tentang pendidikan anak. Dalam Interlinear Greek New Testament, Surat Efesus 6:1-4 dituliskan demikian

${ }^{32}$ Matthew Henry, Tafsiran Matthew Henry: Injil Matius 15-28, Terj. Herdian Apriliani, dkk. (Surabaya: Momentum, 2008), 946-947.

${ }^{33}$ Henry, Tafsiran Matthew Henry: Injil Markus, 219-220.

${ }^{34}$ Matthew Henry, Tafsiran Matthew Henry: Injil Lukas 13-24, Terj. Herdian Apriliani, dkk. (Surabaya: Momentum, 2008), 687-688.

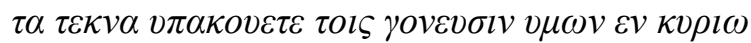


$\tau \eta v \mu \eta \tau \varepsilon \rho \alpha \eta \tau \imath \varsigma \varepsilon \sigma \tau \imath v \varepsilon v \tau o \lambda \eta \pi \rho \omega \tau \eta \varepsilon v \varepsilon \pi \alpha \gamma \gamma \varepsilon \lambda \imath \alpha$

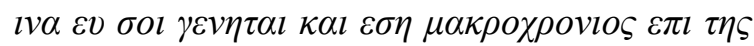
$\gamma \eta \varsigma \kappa \alpha l$ ol $\pi \alpha \tau \varepsilon \rho \varepsilon \varsigma \mu \eta \pi \alpha \rho o \rho \gamma l \zeta \varepsilon \tau \varepsilon \tau \alpha \tau \varepsilon \kappa v \alpha v \mu \omega \nu$ $\alpha \lambda \lambda \quad \varepsilon \kappa \tau \rho \varepsilon \varphi \varepsilon \tau \varepsilon \quad \alpha v \tau \alpha \quad \varepsilon v \quad \pi \alpha l \delta \varepsilon l \alpha \quad \kappa \alpha l \quad v o v \theta \varepsilon \sigma l \alpha$ кvрiov. ${ }^{35}$

Dalam Alkitab terjemahan Bahasa Indonesia ayat tersebut dituliskan demikian

Hai anak-anak, taatilah orangtuamu di dalam Tuhan, karena haruslah demikian. Hormatilah ayahmu dan ibumu -- ini adalah suatu perintah yang penting, seperti yang nyata dari janji ini: supaya kamu berbahagia dan panjang umurmu di bumi. Dan kamu, bapa-bapa, janganlah bangkitkan amarah di dalam hati anak-anakmu, tetapi didiklah mereka di dalam ajaran dan nasihat Tuhan. $^{36}$

Istilah anak-anak (Yun.: $\tau \varepsilon \kappa v o v$, teknon, bisa mengarah juga pada anak-anak yang sudah dewasa) ${ }^{37}$ dalam ayat tersebut sebuah harapan dimana anak-anak menghormati orangtua, khususnya ayah, dan menjaga otoritas keluarga bahkan sampai mati. ${ }^{38}$ Timbal balik dari hal itu adalah bapa-bapa, janganlah bangkitkan amarah atau janganlah membangkitkan amarah (Yun.: $\pi \alpha \rho o \rho \gamma l \zeta \omega$, parorgizo) di dalam hati anak-anakmu.

Peter T. O'Brien dalam tafsiran Surat Efesus menjelaskan bahwa dalam ayat tersebut ada sebuah nasihat positif mendidik anak-anak dalam ajaran dan nasihat Allah. Hal tersebut mengingatkan pada penekanan yang lebih dalam pada tradisi pengajaran Kristen. Dalam ayat tersebut, Paulus membahas tentang sebuah tugas timbal balik anak-anak dan orang tua. ${ }^{39}$ Anak-anak harus dididik menjadi anak yang taat dan bersikap hormat pada orangtua. Berkaitan dengan ketaatan, Solomon menjelaskan bahwa jauh sebelum surat ini ditulis, Yesus Kristus telah menun-

\footnotetext{
35 "Interlinear Greek New Testament."

${ }^{36}$ Efesus 6:1-4.

${ }^{37}$ Strong, The New Strong's Exhaustive,s.v.

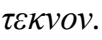

${ }^{38}$ O'Brien, Surat Efesus, 537.

${ }^{39}$ Peter T. O'Brien, Surat Efesus, Terj. Andri Kosasih (Surabaya: Momentum, 2013), 536.
} 
jukkan ketaatan ketika berusia 12 tahun (Luk. 2:4151). Dalam peristiwa itu, Yesus tertinggal di Bait Allah dan akhirnya Maria menegur Yesus. Yesus kemudian menjelaskan bahwa Dia harus berada di rumah Bapa-Nya, tetapi itu tidak dipahami orangtuaNya. Walau demikian, Ia taat pada orangtuanya dan kembali dalam pengasuhan orangtuanya. ${ }^{40}$

Dari hal ini dapat dilihat bahwa anak-anak harus menghormati sekaligus taat kepada orang tua dan sebelum itu orang tua harus mendidik anak-anak agar mereka menjadi taat dan menjadi contoh yang dapat dihargai agar tidak menimbulkan amarah dalam hati anak. Prinsip pendidikan yang terkandung dalam ayat ini adalah (1) orangtua mengambil peran penting dalam pendidikan anak; (2) pendidikan kepada anak merupakan sebuah proses transfer pengetahuan dan penanaman nilai-nilai kehidupan.

Selain para orangtua, Warren W. Wiersbe menjelaskan bahwa Paulus juga melakukan sebuah proses pendidikan. Secara tidak langsung, saat Surat Efesus dibacakan anak-anak hadir dalam persekutuan. ${ }^{41}$ Dalam konteks persekutuan (gereja), Paulus melaksanakan pendidikan kepada anak-anak dengan memberikan nasihat agar anak-anak taat dan hormat kepada orangtua, sementara itu Paulus memberikan pekerjaan rumah bagi orang tua agar memelihara atau dalam hal ini mendidik mereka menjadi taat. Yang menjadi alasan pentingnya mengajar ketaatan pada anak-anak, Wiersbe menyatakan ada empat alasan yaitu (1) Mereka adalah orang-orang Kristen (Ef. 5:21); (2) Ketaatan adalah benar; (3) Ketaatan merupakan perintah (Ef. 6:2); dan (4) Ketaatan membawa berkat (Ef. 6:2-3). Bagi Wiersbe, alasan mengapa anak-anak harus taat dan hormat pada orang tua adalah karena orang tua (ibu) melahirkan anak dan karena orang tua telah memiliki lebih banyak penge-

\footnotetext{
${ }^{40}$ Robert M. Solomon, Kitab Efesus, Yesus dan Jemaat-Nya (Jakarta: Duta Harapan Dunia, 2016), 70.

${ }^{41}$ Warren W. Wiersbe, Kaya Di Dalam Kristus (Bandung: Kalam Hidup, 2001), 141.
}

tahuan serta kebijaksanaan maka patutlah anak-anak menghormati orang tua. ${ }^{42}$

\section{Surat Kolose 3:20}

Demikian pula dalam suratnya kepada jemaat Kolose, Paulus menuliskan tentang anak-anak yang harus taat pada orang tua. Ayat Kolose 3:20 dalam Interlinear Greek New Testament dituliskan de-

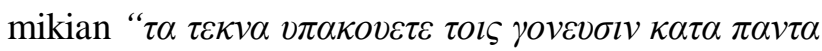

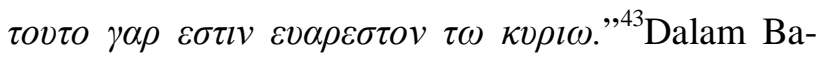
hasa Indonesia ayat tersebut diterjemahan demikian, "Hai anak-anak, taatilah orangtuamu dalam segala hal, karena itulah yang indah di dalam Tuhan." 44 Ayat tersebut paralel dengan Efesus 6:1-4, berbicara tentang kewajiban anak-anak kepada orang tua. Dalam Interlinear Greek New Testament, kata anak yang digunakan adalah $\tau \varepsilon \kappa v \alpha$ sama seperti dalam Surat Efesus 6:1.

Ayat dalam Efesus 6:1 dan Kolose 3:20 sangat berkaitan dengan Taurat Tuhan (Kel. 20:12). Mike Raiter menjelaskan bahwa, dalam tradisi orang Yahudi tidak menghormati orang tua berarti juga tidak menghormati Tuhan. ${ }^{45}$ Itu sebabnya Paulus menekankan kembali pentingnya anak bersikap taat dan menghormati orang tua. Matthew Henry menjelaskan bahwa anak-anak harus taat kepada orang tua karena orang tua memiliki hak secara alamiuntuk mengarahkan anak-anak dari pada diri mereka sendiri. ${ }^{46}$ Jadi orang tua memiliki kewenangan untuk mengarahkan anak-anak agar hidup mereka dapat diarahkan dan menjadi taat. Lebih lanjut Matthew Henry menjelaskan bahwa jangan kiranya orang tua menggunakan kekuasaannya pada anak-anak menyebabkan bangkit-

${ }^{42}$ Ibid, 142-143.

43" Interlinear Greek New Testament."

${ }^{44}$ Kolose 3:20

${ }^{45}$ Mike Raiter, Kitab Kolose \& Filemon, Bertambah Teguh dalam Tuhan (Jakarta: Duta Harapan Dunia, 2016), 50.

${ }^{46}$ Matthew Henry, Tafsiran Matthew Henry: Surat Galatia, Efesus, Filipi, Kolose, 1\&2 Tesalonika, 1\&2 Timotius, Titus, Filemon, Terj. Iris Ardaneswari, dkk. (Surabaya: Momentum, 2015), 404-405. 
nya amarah dalam diri anak atau menyebabkan mereka menjadi tawar hati. ${ }^{47}$ Sementara itu Warren W. Wiersbe menekankan bahwa bagian Kolose 3:20 dan Efesus 4:1-4, anak memiliki hak untuk dibesarkan dalam ajaran dan nasihat Tuhan. Lebih lanjut dijelaskannya bahwa apabila anak tidak belajar menaati orangtuanya maka anak akan sulit untuk bertumbuh dalam ketaatan kepada otoritas apapun. ${ }^{48}$ Oleh sebab itu, pendidikan anak, menjadi tugas penting bagi orangtua dan pendidikan anak menjadi sebuah proses untuk menanamkan nilai-nilai kekristenan.

Raiter memberikan sebuah refleksi dari ayat tersebut sebagai berikut

Di zaman kuno, para ayah memiliki kuasa mutlak atas anak-anak mereka, bahkan atas hidupmati mereka. Pada masa kini, orangtua masih memiliki kuasa yang sangat besar dari segi fisik, emosional, dan psikologis atas anak-anak mereka, dan kuasa itu dapat disalahgunakan dengan cara yang mengerikan. Oleh sebab itu, janganlah membuat anak-anak... sakit hati. ${ }^{49}$

Dari refleksi yang dikemukakan olen Raiter maka dalam menggunakan kuasa yang dimiliki para orangtua, sebaiknya kuasa tersebut digunakan untuk menanamkan nilai-nilai kekristenan pada anak-anaknya.

\section{PEMBAHASAN}

Berdasarkan hasil penelitian, tampak bahwa pendidikan anak adalah sesuatu yang penting untuk dilakukan, kemudian ada tiga prinsippenting untuk pendidikan anak yaitu pendidikan sebagai proses penanaman iman, pendidikan sebagai proses transfer pengetahuan, dan pendidikan sebagai proses penanaman nilai.

\section{Pendidikan sebagai Proses PenanamanIman}

Dari hasil penelitian di atas, penulis melihat bahwa pendidikan anak merupakan sebuah proses penanaman iman. Dalam kitab Keluaran 12:24-27 tampak bahwa orang tua dituntut untuk mendidik

\footnotetext{
${ }^{47}$ Ibid.

${ }^{48}$ Wiersbe, Utuh Di Dalam Kristus, 110-111.

${ }^{49}$ Raiter, Kitab Kolose \& Filemon, 50.
}

anak-anaknya agar beribadah pada Allah. Sama halnya dengan dalam Kitab Ulangan 6:4-9 yang menunjukkan bahwa orangtua diperintahkan untuk mengajarkan iman mereka dengan tekun kepada anak-anak mereka. Kemudian pendidikan tersebut harus dilakukan secara terus menerus (Maz. 78:5-6).

Berdasakan hasil penelitian di atas, tampak jelas bahwa Alkitab menuntut orang tua dan para pengajar untuk menanamkan serta memupuk iman percaya kepada Allah. Orang tua dan pengajar dituntut untuk mendidik anak-anak bersikap takut akan Tuhan sebagai wujud iman percaya pada Allah. Orang tua diberi kuasa mutlak untuk menanamkan iman percaya pada Allah kepada anak-anaknya. Untuk dapat menanamkan iman pada anak, orang tua maupun pendidik harus menghindari perbuatan yang membuat anak-anak sakit hati.

\section{Pendidikan sebagai Proses Transfer Pengetahuan}

Melalui proses pendidikan yang dilakukan di dalam keluarga, anak-anak mengalami transfer pengetahuan akan perbuatan-perbuatan Allah yang besar di tengah bangsa Israel. Anak-anak mendapatkan pengetahuan akan karya keselamatan yang disediakan Allah bagi umat pilihan-Nya. Orang tua memberitahukan secara berulang-ulang dan terusmenerus kepada anak-anak mereka segala perintah dan ketetapan Allah dalam Taurat Musa. Anak-anak mengetahui cara hidup yang Allah kehendaki agar dilakukan oleh umat Israel. Mereka diajarkan arti kekudusan hidup yang sungguh-sungguh berkenan kepada Allah. Hanya Allah satu-satunya yang harus mereka sembah, tidak ada yang lain. Anak-anak tahu akibat dari ketidaktaatan dalam melakukan segala perintah Allah mendatangkan hukuman bagi mereka. Namun Allah yang telah memilih bangsa Israel menjadi umat pilihan-Nya, sungguh-sungguh Allah yang setia akan janji-Nya. Pemeliharaan dan perlindungan Allah bagi umat-Nya benar-benar nyata.

Pengetahuan yang diberikan orang tua kepada anak-anak mereka dilakukan melalui berbagai cara. Para orang tua diperintahkan untuk selalu membicarakan segala ketetapan dan perintah Allah bagi umat pilihan-Nya kepada anak-anak mereka. 
Dalam setiap kesempatan anak-anak akan belajar dan mendapatkan pengetahuan tentang perbuatanperbuatan ajaib yang telah dilakukan Allah bagi bangsa Israel. Segala pengetahuan yang mereka peroleh di dalam keluarga, harus mereka ingat dan meneruskan pengetahuan itu kepada generasi yang selanjutnya.

\section{Pendidikan sebagai Proses Penanaman Nilai}

Pendidikan anak merupakan suatu proses penanaman nilai. Dalam Perjanjian Lama penanaman nilai-nilai kebenaran di dalam pendidikan anak diberikan dalam berbagai cara. Allah secara langsung memerintahkan Musa untuk menyampaikan segala ketetapan dan perintah Allah kepada bangsa Israel. Setiap keluarga di bangsa Israel diperintahkan untuk memelihara segala ketetapan dan perintah Allah dalam ibadah keluarga. Di dalam ibadah keluarga, setiap orang tua diperintahkan untuk selalu menceritakan arti korban Paskah kepada anak-anak mereka.

Para orang tua harus menjelaskan nilai kebenaran yang terkandung dalam pengorbanan Paskah ketika Tuhan melewati rumah-rumah orang Israel saat Ia menulahi orang Mesir. Anak-anak memperoleh pemahaman akan kebesaran kuasa Allah dalam karya penyelamatan bangsa Israel dari perbudakan di Mesir. Oleh tangan Tuhan yang kuat dan perkasa, bangsa Israel telah dibawa kepada kebebasan dan kemerdekaan. Paskah senantiasa menjadi peringatan akan Tuhan sebagai pembebas umat-Nya.

Melalui ibadah yang dilakukan di dalam setiap keluarga, orang tua harus mengajarkan kepada anak-anaknya, bahwa untuk sebuah kebebasan harus ada pengorbanan. Kematian anak sulung dari Raja Mesir dan rakyatnya hingga hewan-hewan mereka merupakan korban yang membawa kebebasan bagi bangsa Israel. Allah yang perkasa menyatakan kuasa kebesaran-Nya saat menuntun bangsa Israel keluar dari tanah Mesir.

Setiap orang tua harus mengajarkan anakanak mereka akan perintah serta ketetapan Tuhan Allah Israel. Anak-anak dididik untuk mengerti dan memahami sifat Allah yang esa. Bahwa Allah telah memerintahkan kepada bangsa Israel untuk mengasihi Tuhan Allah dengan segenap hatimu, segenap jiwamu dan dengan segenap kekuatanmu. Pengajaran dan pendidikan yang dilakukan orang tua kepada anak-anaknya secara terus-menerus dan berulangulang. Bahkan perintah dan ketetapan Allah harus menjadi tanda dan lambang yang dapat dilihat serta dituliskan pada tiang pintu rumah dan pada pintu gerbang.

Pengajaran akan segala perintah Allah yang dilakukan oleh orang tua kepada anak-anak mereka merupakan suatu peringatan yang berkesinambungan. Dari satu angkatan kepada angkatan berikutnya dilakukan secara terus-menerus. Sehingga anak-anak yang menerima pengajaran ini akan mengingat hal ini dan akan mengajarkannya pada angkatan berikutnya. Dengan demikian segala ketetapan dan perintah Allah akan tetap terpelihara dari keturunan ke keturunan secara berkesinam-bungan.

\section{KESIMPULAN}

Dari hasil penelitian yang penulis lakukan, ada beberapa kesimpulan penting yaitu:

Pertama,Ayat-ayat Alkitab berbicara tentang pentingnya pendidikan anak. Dalam Perjanjian Lama kitab Keluaran, Ulangan, dan Mazmur memberikan penekanan tentang pendidikan anak. Dalam Perjanjian Baru, Yesus Kristus menaruh sebuah perhatian penting bagi anak-anak. Demikian pula dalam surat-surat Paulus, Efesus dan Kolose, ada sebuah perhatian terhadap anak dan pendidikan anak.

Kedua, Dalam perspektif Alkitab ada tiga prinsip penting yang dapat diperoleh yaitu (1) pendidikan anak merupakan sebuah proses penanaman iman; (2) pendidikan anak merupakan sebuah proses transfer pengetahuan; dan (3) pendidikan adalah sebuah proses penanaman nilai-nilai kekristenan.

Dari penelitian yang penulis lakukan, penulis dapat memberikan saran bagi peneliti lain yaitu, perlu diteliti bagaimana pelaksanaan tiga prinsip penting tersebut diimplementasikan dalam pendidikan masa kini. 


\section{DAFTAR RUJUKAN}

Alkitab Edisi Studi.Jakarta: LAI, 2012.

Alkitab, Terjemahan Baru. Jakarta: LAI, 2008.

Biblical Hebrew Teks With Vowel Points, SABDA (OLB versi Indonesia) Versi 4.30, 6 September 2013.

Dwikurnaningsih, Yari. "Peran Guru Dalam Pendidikan Anak." Satya Widya. Volume 27, Nomor 2, (Desember 2011): 233-244.

Henry, Matthew. Tafsiran Matthew Henry: Injil Lukas 13-24, Terj. Herdian Apriliani, dkk. Surabaya: Momentum, 2008.

Henry, Matthew. Tafsiran Matthew Henry: Injil Markus, Terj. Lanny Murtihardjana, dkk. Surabaya: Momentum, 2011.

Henry, Matthew. Tafsiran Matthew Henry: Injil Matius 15-28, Terj. Herdian Apriliani, dkk. Surabaya: Momentum, 2008.

Henry, Matthew. Tafsiran Matthew Henry: Kitab Mazmur 51-100,Terj. Iris Ardaneswari, dkk. Surabaya: Momentum, 2012.

Henry, Matthew. Tafsiran Matthew Henry: Surat Galatia, Efesus, Filipi, Kolose, 1 \& 2 Tesalonika, $1 \& 2$ Timotius, Titus, Filemon, Terj. Iris Ardaneswari, dkk. Surabaya: Momentum, 2015.

Interlinear Greek New Testament, SABDA (OLB versi Indonesia) Versi 4.30, 6 September 2013.

Morris, Leon. Injil Matius. Surabaya: Momentum, 2016.

Nggoro, Adrianus Marselus. "Filosifi Wuat Wa'i Budaya Manggarai Dari Perspektif Demokrasi Pancasila." Jurnal Pendidikan dan Kebudayaan Missio. Volume 7, Nomor 1, (Januari 2015):102-113.
O’Brien, Peter T. Surat Efesus, Terj. Andri Kosasih. Surabaya: Momentum, 2013.

Raharjo, Sabar Budi. "Evaluasi Trend Kualitas Pendidikan di Indonesia." Jurnal Penelitian dan Evaluasi Pendidikan. Tahun 16, Nomor 2, (2012):511-532.

Raiter, Mike. Kitab Kolose \& Filemon, Bertambah Teguh dalam Tuhan. Jakarta: Duta Harapan Dunia, 2016.

Rifa'i RC, Achmad. "Model Pengelolaan Program Pendidikan Anak Usia Dini Berbasis Masyarakat." Jurnal Ilmu Pendidikan. Volume 19, Nomor 1, (Juni 2013):120-127.

Scheunemann, Rainer. Panduan Lengkap Penafsiran Alkitab Perjanjian Lama \&Perjanjian Baru, Menafsirkan Alkitab dengan Metode IlmiahEksegetis. Yogyakarta: PBMR Andi, 2009.

Solomon, Robert M. Kitab Efesus, Yesus dan JemaatNya. Jakarta: Duta Harapan Dunia, 2016.

Stamps, Donald C. "Paskah." Alkitab Penuntun Hidup Berkelimpahan. Jakarta: LAI bekerjasama dengan Gandum Mas, 2003.

Stamps, Donald C. Catatan kaki padaAlkitab Penuntun Hidup Berkelimpahan. Jakarta: LAI bekerjasama dengan Gandum Mas, 2003.

Strong, James. The New Strong's Exhaustive Concordance of The Bible. London: Thomas Nelson Publishers, 1984.

Wiersbe, Warren W. Utuh Di Dalam Kristus. Bandung: Kalam Hidup, 2001.

Wiersbe, Warren W. Kaya Di Dalam Kristus. Bandung: Kalam Hidup, 2001. 